\title{
Exome sequencing expands the mutational spectrum of SPG8 in a family with spasticity responsive to L-DOPA treatment
}

\author{
Conceição Bettencourt • Huw R. Morris • \\ Andrew B. Singleton • John Hardy • \\ Henry Houlden
}

Received: 19 June 2013/Revised: 10 July 2013/Accepted: 11 July 2013/Published online: 24 July 2013

(C) The Author(s) 2013. This article is published with open access at Springerlink.com

Dear Sirs,

Hereditary spastic paraplegias (HSPs) are clinically and genetically heterogeneous. Pure forms are characterized primarily by progressive spasticity and weakness of the lower limbs. Complicated forms, however, involve neuronal systems other than corticospinal tracts, namely peripheral nerves, and sensory or cerebellar pathways [2]. At least 52 loci and 31 causative genes are known, and thus a gene-by-gene diagnostic approach is becoming impractical. For the 19 autosomal dominant forms (AD-HSPs), 11 genes are known, with SPG4 being by far the most common subtype (40-45\% AD-HSP cases) [4]. The vast heterogeneity in HSP makes a genetic diagnosis difficult and expensive. Many research groups have used gene panels or targeted sequencing but the rapid growth and frequent identification of new genes makes this difficult.

We studied a female patient presenting familial spastic paraplegia with sensory axonal neuropathy, compatible with AD inheritance (Fig. 1a). At the age of 10 years she developed problems walking and subsequently had many surgical procedures on her feet. After a pregnancy at the age of 42 , she became more tired and walking slowed down with more pain. She has significant spasticity and sensory symptoms in her feet, burning, redness, occasionally whiteness, and she is often in extreme pain and discomfort. Both brain and spinal cord MRI scans were normal. She

C. Bettencourt $(\bowtie) \cdot$ H. R. Morris $\cdot$ J. Hardy $\cdot$ H. Houlden Department of Molecular Neuroscience, UCL Institute of Neurology, Queen Square, London WC1N 3BG, UK e-mail: c.bettencourt@ucl.ac.uk

A. B. Singleton

Laboratory of Neurogenetics, National Institute on Aging,

National Institutes of Health, Bethesda, USA was started on L-DOPA (Co-Careldopa 25/100 mg tds), as one of the differential diagnoses was dopamine responsive dystonia, which was very helpful for her spasms and sensory symptoms in her feet. Additionally, she had bladder urgency and skin features to suggest autonomic dysfunction, and her gait was typical of spastic paraplegia. Her daughter reported early problems presenting at the age of 19, with pain in her feet and in the back of her legs, spasticity, cramps and sensory symptoms. Her gait showed a slight inversion of the right foot on walking. Interestingly, the daughter had tried L-DOPA in the form of CoCareldopa 25/100 mg with benefit to her spasticity similar to her mother. The proband's mother was also thought to have feet problems, with cold and stiff painful feet as well as abnormal sensation but her presentation was late in her mid-50s with very slow deterioration.

Although whole-exome sequencing is still expensive, and not everywhere available, it has been shown to be a useful tool for the diagnosis of complicated HSP [1]. Using this approach, we identified a novel KIAA0196 missense variant in the proband (c.677T $>$ C, p.I226T). By Sanger sequencing, her daughter was shown to have the same variant (Fig. 1b). This variant is predicted as damaging by SIFT, is located in a conserved residue (Fig. 1c), and is not present in more than 200 in-house exomes or in public databases, such as dbSNP, 1000 Genomes Project, and the Exome Variant server (http://evs.gs.washington.edu/EVS/).

The KIAA0196 gene (MIM\#610657) is responsible for SPG8 (MIM\#603563), a rare AD-HSP, and encodes for strumpellin, a protein that participates in the WASH complex, acting at the interface between actin regulation and endosomal membrane dynamics [5]. There are only two reports of mutations in this gene [3, 8], one of them recently published in this journal. Overall, there are seven SPG8 families, usually with pure phenotypes, and four 


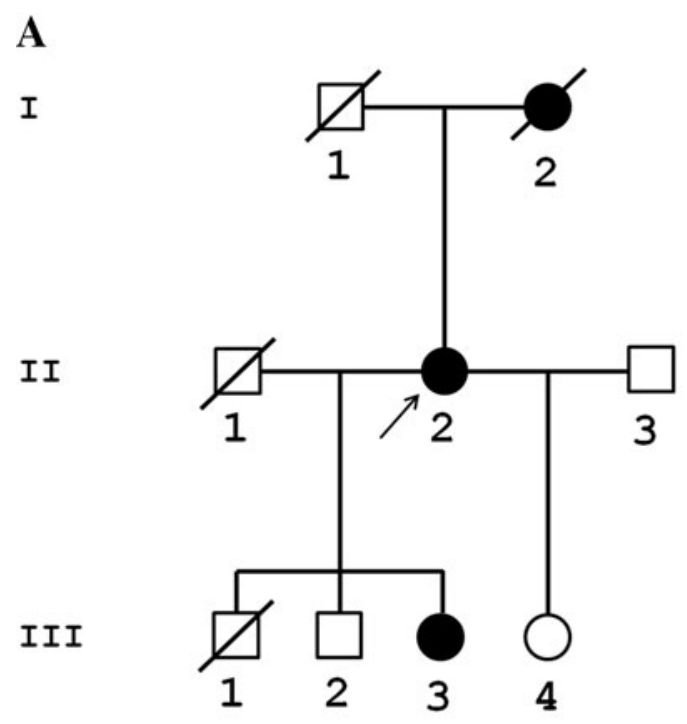

Fig. 1 a Pedigree of a UK family with spastic paraplegia. The arrow points to the proband. Black and white symbols indicate affected and unaffected individuals, respectively. b Electropherograms illustrating the novel KIAA0196 missense variant (c.677T > C, p.I226T)
B

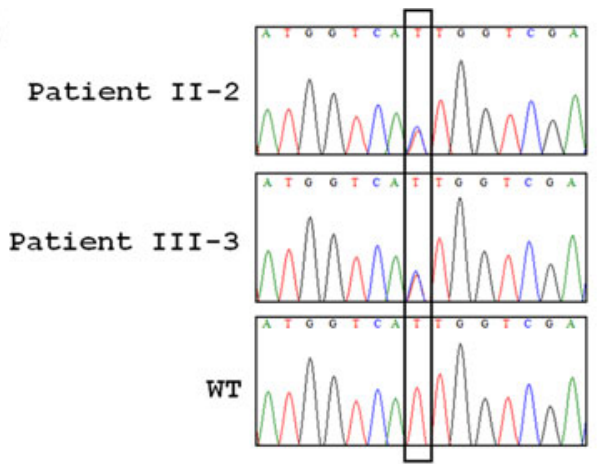

C

Human
Chimpanzee
Macaque
Dog
Cat
Caw
Mouse
Zebrafish
C. elegans

identified in our family. c Sequence alignment of WASH complex subunit strumpellin, which is encoded by the KIAA0196 gene, showing the conservation between species in the mutated position

Table 1 Mutations in the KIAAO196 gene identified in HSP families

\begin{tabular}{|c|c|c|c|c|c|c|c|c|c|}
\hline \multirow[t]{3}{*}{ Mutation } & \multicolumn{7}{|c|}{ Phenotype } & \multirow{3}{*}{$\begin{array}{l}\text { Number } \\
\text { of } \\
\text { families }\end{array}$} & \multirow[t]{3}{*}{ Reference } \\
\hline & \multirow{2}{*}{$\begin{array}{l}\text { Onset } \\
\text { (years) }\end{array}$} & \multirow{2}{*}{$\begin{array}{l}\text { Pure/ } \\
\text { complicated }\end{array}$} & \multicolumn{4}{|c|}{ Lower limbs } & \multirow[t]{2}{*}{ Other } & & \\
\hline & & & Spasticity & Hyperreflexia & Weakness & $\begin{array}{l}\text { Babinski } \\
\text { sign }\end{array}$ & & & \\
\hline $\begin{array}{l}\text { c. } 677 \mathrm{~T}>\mathrm{C} \\
\text { p.I226T }\end{array}$ & $10-55$ & Complicated & + & + & Distal & + & $\begin{array}{l}\text { Sensory axonal } \\
\text { neuropathy, dopamine } \\
\text { responsive spasticity, } \\
\text { urinary urgency }\end{array}$ & 1 & $\begin{array}{c}\text { Present } \\
\text { study }\end{array}$ \\
\hline $\begin{array}{l}\text { c. } 1491 \mathrm{~A}>\mathrm{G} \\
\text { p.N471D }\end{array}$ & $22-29$ & n.a. & n.a. & n.a. & n.a. & n.a. & n.a. & 1 & {$[8]$} \\
\hline $\begin{array}{l}\text { c. } 1937 \mathrm{G}>\mathrm{C} \\
\text { p.L619F }\end{array}$ & $18-26$ & Pure & + & + & + & + & Bladder dysfunction & 1 & {$[7,8]$} \\
\hline $\begin{array}{l}\text { c. } 1956 \mathrm{G}>\mathrm{T}, \\
\text { p.V626F }\end{array}$ & $20 s-60 s$ & Pure & n.a. & + & n.a. & n.a. & $\begin{array}{l}\text { Impaired vibratory sense, } \\
\text { urinary urgency }\end{array}$ & 4 & {$[6,8]$} \\
\hline $\begin{array}{c}\text { c. } 2087 \mathrm{G}>\mathrm{C}, \\
\text { p.G696A }\end{array}$ & $21-57$ & Pure & + & + & + & + & $\begin{array}{l}\text { Impaired vibratory sense, } \\
\text { urinary urgency }\end{array}$ & 1 & {$[3]$} \\
\hline
\end{tabular}

+ present, $n . a$. information not specified in the reference

pathogenic mutations identified worldwide (Table 1). Our pedigree is compatible with an AD-HSP, and the variant we found in the KIAA0196 gene, segregating with the phenotype, is most likely causing HSP. The response to LDOPA is interesting and may suggest an overlap of the functional pathway of KIAAO196 and dopamine. Although the knowledge of the underlying mutation does not change the therapeutic strategy, it is valuable on what concerns genetic counseling. We therefore identified the eighth SPG8 family and the fifth mutation by making use of nextgeneration sequencing. Furthermore, we report a complicated phenotype, with an earlier onset than those previously reported (Table 1), also expanding the clinical spectrum of SPG8. 
Acknowledgments We are grateful to the Medical Research Council (MRC), the Parkinson's Disease Foundation (PDF), The Brain Research Trust (BRT), The Wellcome Trust/MRC Parkinson's disease consortium grant, and the UCL/UCLH NIHR biochemical research centre (BRC).

Conflicts of interest On behalf of all authors, the corresponding author states that there are no conflicts of interest.

Ethical standard This study was performed in accordance with the ethical standards laid down in the 1964 Declaration of Helsinki.

Open Access This article is distributed under the terms of the Creative Commons Attribution License which permits any use, distribution, and reproduction in any medium, provided the original author(s) and the source are credited.

\section{References}

1. Bettencourt C, Lopez-Sendon JL, Garcia-Caldentey J, Rizzu P, Bakker IMC, Shomroni O, Quintáns B, Davila JR, Bevova MR, Sobrido M-J, Heutink P, Garcia de Yebenes J (2013) Exome sequencing is a useful diagnostic tool for complicated forms of hereditary spastic paraplegia. Clin Genet (in press)

2. Bettencourt C, Quintans B, Ros R, Ampuero I, Yanez Z, Pascual SI, de Yebenes JG, Sobrido MJ (2012) Revisiting genotype- phenotype overlap in neurogenetics: triplet-repeat expansions mimicking spastic paraplegias. Hum Mutat 33:1315-1323

3. de Bot ST, Vermeer S, Buijsman W, Heister A, Voorendt M, Verrips A, Scheffer H, Kremer HP, van de Warrenburg BP, Kamsteeg EJ (2013) Pure adult-onset spastic paraplegia caused by a novel mutation in the KIAA0196 (SPG8) gene. J Neurol 260:1765-1769

4. Finsterer J, Loscher W, Quasthoff S, Wanschitz J, Auer-Grumbach M, Stevanin G (2012) Hereditary spastic paraplegias with autosomal dominant, recessive, $\mathrm{X}$-linked, or maternal trait of inheritance. J Neurol Sci 318:1-18

5. Freeman C, Seaman MN, Reid E (2013) The hereditary spastic paraplegia protein strumpellin: characterisation in neurons and of the effect of disease mutations on WASH complex assembly and function. Biochim Biophys Acta 1832:160-173

6. Reid E, Dearlove AM, Whiteford ML, Rhodes M, Rubinsztein DC (1999) Autosomal dominant spastic paraplegia: refined SPG8 locus and additional genetic heterogeneity. Neurology 53:1844-1849

7. Rocco P, Vainzof M, Froehner SC, Peters MF, Marie SK, PassosBueno MR, Zatz M (2000) Brazilian family with pure autosomal dominant spastic paraplegia maps to 8q: analysis of muscle beta 1 syntrophin. Am J Med Genet 92:122-127

8. Valdmanis PN, Meijer IA, Reynolds A, Lei A, MacLeod P, Schlesinger D, Zatz M, Reid E, Dion PA, Drapeau P, Rouleau GA (2007) Mutations in the KIAA0196 gene at the SPG8 locus cause hereditary spastic paraplegia. Am J Hum Genet 80:152-161 